The Wild Canids: Their Systematics, comprehensive. As Michael Fox says in Xenopus. Chapters devoted to the last of Behavioral Ecology and Evolution. Edited his conclusion, one of the aims of the these subjects take up half of the book by $\mathrm{M}$. W. Fox. Pp. xvi +508 . (Van book is to reduce man's alienation from and provide an admirable review of Nostrand Reinhold: New York and Lon- nature. It should help. don, March 1975.) $£ 10.60$.

Juliet Clutton-Brock

UNTIL very recently no comprehensive review of the wild members of the dog family had been published since iMivart wrote his Monograph of the Canidae in 1890. Now two books on the subject have become available. The first, Lois E. Bueler's Wild Dogs of the World (Collins, London, 1974), is an excellent popular book; it is well complemented by the second, a more technical work entitled The Wild Canids. This latter volume is based on behavioural studies within a framework of five sections: taxonomy, behaviour, genetics, ecology, and the evolution of behaviour. Much of the work has been published before but this does not detract from the value of the book as a review.

The ethology and ecology of the northern races of the wolf, Canis lupus, have been studied in detail over the past decade and are well reviewed again here; and a new approach is used in a chapter on the Eskimo hunter's view of the wolf. There is still, however, a lack of any information on social structures in the Indian and Arabian races of the wolf and, as it is probable that these were the main progenitors of the domestic dog and the dingo, it would be most interesting to learn more about their social organisation (touched on by Lorenz in the foreword). Corbett and Newsome show that the dingo is not highly social and is a solitary hunter; whether this type of behaviour evolved since the dingo became feral in Australia, or whether it was inherent in their ancestors, provides a fascinating enigma to add to Macintosh's chapter on the origin of that animal.

Observations on the behaviour of the coyote, Canis latrans, and on some of the less well known canids, for example, the South American foxes and the Indian dhole, Cuon alpinus, are disappointingly slight. Lawrence and Bossert produce interesting evidence in support of hybridisation in the North American species of Canis. This work exemplifies an interesting aspect of canid behaviour that emerges in several parts of the book. This is the ability of certain species to have a close interaction with man (and with the domestic dog, with which the wolf, coyote, jackal, and dingo will all interbreed). Some species within the generd Canis, Vulpes, and Dusicyon are so flexible in their behaviour and ecological requirements that they can coexist with man and even take advantage of human disturbance to the environment.

The Wild Canids will be of great value to all students of animal behaviour. It has been well edited and the bibliography is

\section{Dogs, frogs and fish}

Xenopus: The South African Clawed Frog. By E. M. Deuchar. Pp. $x+246$. (WileyInterscience: London and New York, February 1975.) $£ 10.25$.

A GLANCE at the list of references within this volume will indicate to the reader how rapidly Xenopus has risen in popularity with research workers in the field of developmental biology.

Xenopus laevis is easy to keep because it is aquatic and thus not averse to life in aquaria, even when it is kept at temperatures much lower than those normally encountered in its African habitat. The male and female can conveniently be induced to mate by the injection of appropriate gonadotrophins which are used for human medication. Dr Deuchar suggests that the sperm may need to swim faster than the sperm of other species because the male and female cloacae are not as close as they are in other anurans during amplexus. But, while collecting freshly laid eggs, I have noticed that the male partner bends his back to bring the cloacae very close when the female is actively laying eggs, but not at other times.

Most research workers concentrate on studies of embryos and tadpoles that need not be as accurately timed as mine, but staging is all important and for this they find, as Dr Deuchar says, that the Normal Table of Xenopus laevis Daudin is invaluable. Even a group of tadpoles that have been reared together will display differences in their rates of development, though they are smaller than the differences between groups reared at different temperatures or on diverse food regimes. It is thus rather meaningless in research to refer to the ages of tadpoles alone instead of to stages which can be quite precisely used by all investigators.

Dr Deuchar has stressed the relative speed of Xenopus development which may be a pleasure to some but a disadvantage to others. The beautiful grace and transparency of the Xenopus tadpole is a delight to all.

She has read a great deal (more than 500 references) in order to produce such present day research into many aspects of the pre-frog life of Xenopus l. laevis.

This book should be made available to all who work in this field. Louie Hamilton

The Early Life History of Fish. (The Proceedings of an International Symposium at Dunstaffnage Marine Research Laboratory, Oban, 1973.) Edited by J. H. S. Blaxter. Pp. $x+765$. (Springer: Berlin and New York, 1974.) DM98; $\$ 40.00$. 500 references) in order to produce such meeting) provides a lasting testimony to anatomy, physiology and development of specialised field.
THis volume contains the collected contributions to a symposium on the early life history of fish held at the Dunstaffnage Marine Research Laboratory at Oban, Scotland, in 1973. Fifty four papers are published in their entirety, with two more in abstract form. The volume (like the symposium) is divided into seven categories (population studies, distribution, feeding and metabolism, physiological ecology, developmental events, behaviour, and taxonomy).

Most of the contributions fall under the heading of population studies, with discussions of egg and larval abundance in relation to fish population dynamics greatly outnumbering the other papers. High mortalities during early life have a potent effect on the recruitment of a year class to a fishery and several contributions are concerned with the causes of this: the interactions of starvation, predation, physical damage, loss to adverse current systems, and imperfections in development, are all discussed. Clearly, the causes are varied and rarely stem from any one factor.

The section on physiological ecology contains several valuable papers on environmental topics. The effects of cadmium on the development and survival of herring eggs, and the effects of thermal shock on larvae entrained in electricity generating station cooling systems, are two papers of particular relevance to fisheries in industrial regions. Another contribution discusses the effects of $\mathrm{H}_{2} \mathrm{~S}$ on the development and survival of larvae in freshwater fishes.

Under the heading 'Rearing', six papers cover techniques related to aquaculture. Variation in temperature and in photoperiod, hormone injection, selective hybridisation, and genetic manipulation all for food and are considered in various contributions.

These wide-ranging topics are typical of the broad spectrum of research into fish eggs and larvae that was presented at the symposium. The editing of this volume (and the organisation of the
Alwyne Wheeler have an obvious relevance to rearing fish 